\title{
IMPROVEMENT OF THE QUALIFICATION OF MUSIC TEACHERS WITH THE USE OF REMOTE DIGITAL EDUCATIONAL TECHNOLOGIES
}

\author{
Dmitrii Rytov, rytovda@mail.ru
}

\author{
Saint-Petersburg State University of Culture, Russia
}

\begin{abstract}
The potential of digital technologies in the system of professional development of music teachers using remote digital educational technologies is revealed. The tendencies of modern use of distance educational technologies, e-learning in solving the issues of preserving the traditions of folk instrumental culture have been demonstrated. Problematic issues of distance education organization have been identified. The resources of the information and educational environment in the system of professional development of music teachers are analyzed. A comprehensive analysis of the main functions of applying digital technologies involved in the preparation of a musician-performer has been identified and made: information, creative, methodological and educational. Specificity of digital educational resources in music-performing activity, in conducting and fixing of researches in the field of performing technique, organology, musical pedagogy, dissemination of pedagogical experience is shown. The competence orientations of performing activity, creative selfregulation are determined. The potential and tendencies of the use of remote forms of conducting scientific and methodological events, the use of electronic training tools, the organization of distance education of the performer on musical instruments are revealed.
\end{abstract}

Keywords: Folk Art Culture, Cultural Heritage, Traditions of Folk Instrumental Culture, Translation of Cultural Values, Digital Technologies, Information Environment, Distance Education 


\title{
ПОВЫШЕНИЕ КВААИФИКАЦИИ ПЕААГОГОВ- МУЗЫКАНТОВ С ПРИМЕНЕНИЕМ АИСТАНЦИОННЫХ ЦИФРОВЫХ ОБРАЗОВАТЕАЬНЫХ ТЕХНОАОГИЙ
}

\author{
Амитрий Рытов, rytovda@mail.ru
}

Санкт-Петербургский государственный институт культуры, Россия

\begin{abstract}
Аннотация: Раскрыт потенциал Аистанционных цифрровых образовательных технологий в системе повышения квалификации пелагогов-музыкантов. Определены компетентностные уровни развития педагога, мотивационные условия в необходимости повышать квалификацию, фрункции Аеятельности педагогамузыканта в системе повышения квалификации. Продемонстрированы тенденции современного электронного обучения, выявлены проблемные вопросы организации Аистанционного образования. Проанализированы ресурсы инфрормационно-образовательной среды в системе повышения квалификации педагогов-музыкантов. Определены и слелан комп^ексный анализ основных функций применения цифровых технологий, участвующих в повышении квалифрикации педагогамузыканта.
\end{abstract}

КАючевые слова: педагог-музыкант, акмеология, профессиональные компетенции, повышение квалификации, цифровое пространство, цифровые технологии, электронное обучение

В условиях существующих проблем современности, ввеАения ряда ограничений, вызванных пандемией COVID-19, возникает ряА вопросов, которые требуют незамедиительного решения, в том числе, в сорере образования и повышения квалифоикации педагогов-музыкантов. КогАа теряются устои, происхолит Аеорормация образа жизни и алекватность восприятия Аействительности, Авижущей силой устойчивости системы образования являются пеАагоги. Качество ^юбой системы образования напрямую связано с уровнем профрессионализма работающих педагогов. 
Они всегла находятся в определенном напряжении, стрессовой ситуации, когАа при возникающих в обществе изменениях, быстрой смене инорормации, стандартов образования, им иногАа не хватает новых профрессиональных компетенций, новых знаний и нового мышления. Постоянное повышение квалификации осознанно или неосознанно стимулирует педагогов $\mathrm{k}$ развитию, а не ведет $\mathrm{k}$ деградации и профрессиональной стагнации.

Компетентностный уровень современного педагога полразумевает наличие творческой инАивиАуальности, профрессиональной харизмы педагога, готового принимать и воспринимать новую инорормацию, работать в системе многозадачности, постоянного обновления и совершенствования инорормационных технологий и на Аеятельностном уровне редрлексировать при решении продрессиональных залач. Аичностные мотивации педагогов и самонацеливание в своей Аеятельности на развитие являются оАним из эорорективных Арайверов повышения качества образования в целом и повышения продрессиональной компетентности кажлого педагога. Осознание ими необходимости повышать свою квалификацию формируется на основе самоанализа своей Аеятельности и выстраивания плана саморазвития, вкАючающего целеполагание и пролвижения по пути Аостижения поставленных залач. В процессе осуществления профрессиональной Аеятельности пеАагог самопроявляет свои профрессиональные качества (имеющиеся и формиирумые), оценивает уровень Аостаточности имеющегося профрессионального инструментария, самокорректирует свои продрессиональные установки и осуществляет свою Аеятельность уже на новом уровне развития. Происхолит восхожАение к продрессиональному самосовершенствованию. Погружение в такую акмеологическую парадигму помогает человеку развиваться на протяжении всей жизни, восходить к новым профрессиональным высотам успеха, как в своей деятельности, так и в ее результатах - через успехи своих учеников. «Акмеологический поАхоА преАполагает выявления условий мобилизации у человека установки на наивысшие Аостижения, на наиболее полную самореализации личности. 
Большое значение придается осознаванию человеком своего инАивиАуального профриля профрессионализма, обАумыванию инАивиАуальных стратегий и траекторий Авижения к профрессионализмул) (Maistrenko and Maistrenko, 2019, р. 10). Становление и развитие пелагога-музыканта обусловлены взаимодействием внутренних (Аичностных) и внешних (социальнопрофрессиональных) фракторов. Самосознание и самоактуализация профрессиональных качеств педагога связаны с внутренними причинами, когАа в процессе педагогической и исполнительскотранслирующей Аеятельности усиливаются продрессиональные мотивационные характеристики. Внешние фракторы связаны с координацией и с уровнем соотнесения с современными требованиями к педагогической Аеятельности, (временными, культурными, социально-политическими и Ар.), что позволяет корректировать внутренние механизмы саморазвития педагога. АОвольно часто хоА истории, социально-эКономические ситуации, возникающие в обществе, Аиктуют определенные установки, которые априори «заставляют» педагога развиться, иначе он не будет соответствовать современным регламентам, предьявляемым к педагогическим работникам, может даже мишиться работы.

Формирование продрессионально-коммуникативной компетенции незаменимо при выстраивании профрессиональных контактов и пелагогического общения. Аля Аостижения поставленных целей на более высоком уровне с проведение внутреннего самоанализа профрессиональной Аеятельности поможет рефрлексивная компетенция. Решение залач в цифровом пространстве с использованием современных возможностей не может быть осуществлено без формирования инорормационнокоммуникационной компетентности.

Компетенции могут быть стратегическими, модульными и ^ока^ьными, в зависимости от уровня сложности поставленных заАач и временного отрезка их актуальности в Аеятельности. Формирование компетенций у педагогов-музыкантов в этой многоуровневой иерархии касаются как выполнения своих Аолжностных, функциональных, 
творческих обязанностей и залач, профрессиональной самореализации в персональных творческих проектах, участия в творческих и инициативных группах (исполнительские практики в ансамблях, оркестрах, участие в музыкальных проектах в качестве постоянной или сессионной творческой еАиницы), решения профрессиональных и залач на уровне переосмысления своей Аеятельности, выработки стратегии саморазвития и самосовершенствования.

Аеятельность пелагога-музыканта в системе повышения квалификации имеет ярко выраженные функции:

1. Репрезентативная. В процессе творческой деятельности в определенной социальной группе (фрормально или нефрормально организованной) происхолит представление своих умений и навыков, сужАений и воззрений. Повышение квалифоикации стимулирует рост индекса качества компетенций педагога вовлеченного в процесс репрезентации своей профрессиональной Аеятельности в этих группах.

2. Социокультурная. В процессе повышения квалифрикации $А \wedge я$ пелагога более четко формируются Аеятельностные профрессиональные ориентиры в конкретной социокультурной среАе. ПровоАником Аля реализации этой функции могут быть различные фрормы общего, Аополнительного, Аистанционного образования, конкретные исполнители, музыкальные явления и мероприятия, влияющие в целом на повышение общекультурных и узкопрофрессиональных компетенций пелагога.

3. Рефлексивная. Реализация потребности в самовыражении в продуктивной Аеятельности, проявления Аичностной активности. Наполнение жизни новыми смыслами через новое осознание своей профрессиональной деятельности. Развитие себя и своих способностей в процессе совершенствования своих навыков и умений, расширение продрессиональных компетенций через ресурсы системы повышения квалификации.

4. Трансляционно-репрезентационная. Активизация и совершенствование в процессе повышения квалификкации механизмов транслирования явлений культуры среАствами музыкального искусства. Репрезентация своих умений, созданных материальных или 
нематериальных продуктов творчества обществу, передача полученных знаний, опыта, приобретенных умений через культурные коммуникации и контакты. Расширение продрессиональных контактов через знакомство с опытом Аругих участников образовательных программ повышения квалифоикации.

7. Компенсаторная. Компенсаторика негативных фокторов, возникающих в жизни современного человека, среАствами музыкального искусства, исполнительской Аеятельности, народного творчества. На ^ичностном уровне компенсаторика проявляется в созАании развивающего поля А^я творческой самореализации. Повышение квалифрикации стимулирует к раскрытию новых каналов постижения и передачи инорормации: человек чувствует свою востребованность и значимость как часть социума, как профрессионаА своего $\Delta е \wedge$.

Современные требования к формированию компетенций прелполагают развитие и совершенствование применяемых технологий образования. В законе Российской Фелерации в общих требованиях к реализации образовательных программ четко прописано, что при реализации образовательных программ используются различные образовательные технологии, в том числе Аистанционные образовательные технологии, электронное обучение. При этом указывается на необхолимость реализации образовательных программ с применением электронного обучения и Аистанционных образовательных технологий, в том числе, с применением инорормационно-телекоммуникационных сетей при опосреАованном (на расстоянии) взаимодействии обучающихся и педагогических работников ${ }^{1}$.

Потенциал цифровых технологий в системе повышения квалифоикации педагогов-музыкантов с применением Аистанционных цифровых образовательных технологий проявляется в соответствующих принципах обучения: принцип паттернирования, реализованного

\footnotetext{
1 Page 31: Ob obrazowanii v Rossiyskoy Federatcii: feder. zakon s izmeneniyami i dopolneniyami na 2019 g. (in Russian) - Moscow: Eksmo, 2019, p. 224 // [Страница 31: Об образовании в Российской Фелерации: фрелер. закон с изменениями и Аополнениями на 2019 г. - Москва: Эксмо, 2019. - 224 с.]
} 
инорормационными и мультимедийными средствами (наличие определенных алгоритмов при выстраивании цепочки «схема-образ» средствами музыкального искусства), принцип оптимизации к^ассических музыкально-педагогических метолик с использованием мультимеАийных технологий, принцип синтеза цифровизации и аналоговых форм хуложественно-творческой коммуникации, обучения и представления исполнительских практик. Цифровые технологии позволяют быстро устанавливать обратную связь межАу субъектами обучения, которые могут взаимодействовать как в чисто Аистанционном формате, так и в смешанных разновиАностях. Положительным элементом является упрощение осуществления инорормационнопоисковой Аеятельности и контрольно-оценочной Аеятельности, применение возможностей автоматизации этих процессов, использования возможностей искусственного интелмекта. НеАостатком является то, что результаты профрессиональной Аеятельности пеАагогов по исполнительским Аисциплинам не могут в полной мере реализовываться только в Аистанционном фрормате.

Т.А. Мерцалова справедливо замечает, что развитие культурных цифровых инструментов ставит перел образованием вопрос, какие фоиические, умственные и психические способности и как нало развивать в холе организованного обучения, а какие из них и в каком объеме следует компенсировать (или подАерживать в ходе их формирования) новыми цифровыми инорормационными инструментами (Uvarov et al., 2019, р. 47). Музыкальное творчество и исполняемые музыкальные произведения невозможно алекватно воспринимать даже при очень качественной компьютерной визуализации и использовании эталонной звуковоспроизводящей и звукоусилительной техники. Результаты Аистанционных фрорм обучения (исполнительские практики) или слушания, просмотр аудио- или вилеороликов в основном передаются в компрессированном форомате звука, с сужением детализации и панорамы, смазанной артикуляцией звучания инструментов, урезанием слышимого человеческим ухом частотного Аиапазона. В итоге происходит снижение восприимчивости интонационной природы музыкального языка, что влияет на 
возникновение Аеструктивных процессов восприятия музыки в целом (Rytov, 2019, p. 139).

Аостоверный энерго-инорормационный откАик АОстижим только при аналоговом воспроизведении и восприятия произведений музыкального искусства. И.П. Подласый утвержАает, что активное телесное поведение способствует энергоинорормационному балансу организма, согласно принципу обратной связи (Podlasai, 2010, р. 39). Что еще раз позволяет залуматься о проблеме механизмов реализации в настоящее время обратных связей между обучающим и обучающимися, в том числе, и в системе повышений квалиорикации педагогов-музыкантов. Констатируем, что Аостижение результатов возможно при практически ежеАневном профрессиональном контакте обучающегося с преподавателями, Аиалоговом обмене инфоомацией, эталонном показе и оперативной корректировке формируемого исполнительского аппарата у обучающегося, ^ичностно-ориентированной и Аетальной отработке исполнительских навыков игры на музыкальном инструменте, поступенчатом и планомерном росте будущего исполнителя-продрессионала. В системе повышения квалифрикации пелагога-музыканта Аолжна быть созАана разумная культуродрормирующая среда, в которой булет Аостигнут оптимальный баланс межАу применяемыми аналоговыми и цифровыми технологиями.

Повышение квалиоикации педагогов-музыкантов очень зависимо от состояния внутренней психолого-пеАагогической комфоортности и удовлетворенности, мотивированности специалистов, как к развитию в профрессии, так и активности в повышении квалифрикации. Существуют вынужленные мотиваторы (аттестационные процеАуры, срок окончания трудового Аоговора, жесткие требования к прохожАению аттестации и Ар.) и мотиваторы Аобровольные (Аичностная неудовлетворенность уровнем квалифрикации и своих профрессиональных качеств, наличие стремления узнать новое, потребность в самообразовании, в саморазвитии), которые позволяют педагогам находиться в тренде новых музыкально-педагогических программ и инорормации, современных образовательных технологий, 
познавать себя в изменяющемся окружающем мире. Вместе с тем существует проблема профрессионального выгорания педагогов (эмоциональная и профрессиональная инфантильность и истощенность, апатия при возникновении ситуаций, требующих быстрого педагогического отклика, преоблалание торможения, а не оперативного Аействия, невосприимчивость к новому, принижение внутренней самооценки). Быстро изменяющееся инорормационное пространство стимулирует пеАагогов к грамотному использованию цифровых образовательных технологий при уловлетворении продрессиональных потребностей и Аостижении мичностных результатов.

Ресурсы современного использования Аистанционных образовательных технологий, электронного обучения в системе повышения квалифокации педагогов-музыкантов Аостаточно широки и продолжают дальнейшее свое развитие и обогащение. Вместе с тем, «листанционное образование анализируется как проблематичная концепция социальной реальности. Новые технологии постоянно развивают образовательные модели, поэтому слеАует ожиАать, что новые революционные метолики станут реальностью. ОАнако быстрые изменения в социальной реальности приводят к утрате структурных балансов и преимуществ Аистанционного обучения» (Gurev, 2018, р. 12). Информационные и Аистанционные образовательные технологии в творческой и в научно-методической Аеятельности находят свое воплощение во время участия педагогов-музыкантов в работе пелагогических коноеренций на специальных образовательных порталах, участия специалистов в вилеоконореренциях, в том числе с помощью приложения Zoom, слушание и проведение лекции на Интернет-площадках А^я проведения онлайн-вебинаров (например, на Webinar.ru), участие и обучение на электронных образовательных п^ощалках (например, проект Министерства культуры Российской Фелерации «Творческие ^юАи», проект Министерства образования и науки Российской ФеАерации и межвузовской площаАки электронного образования «Универсариум» и Ар.), размещение и изучение учебнометодических работ в ЕАиной инорормационной образовательной 
среде (ЕИОС), которая СозАана практически в кажАом высшем учебном заведении России. ОАним из условий повышения квалификации педагогов-музыкантов является создание и публикацию своих научно-методических материалов в интернете (специальные образовательные порталы, цифрровые научно-метолические ресурсы, сайты образовательных организаций, социальные сети, и Ар.). Большую помощь при решении вопросов повышения квалифоикации имеет участие в вебинарах, когла в режиме реального времени можно не только получить информацию, но и залать интересующие вопросы, получить экспресс-консультирование.

Все большую популярность приобретает повышение квалифоикации с вылачей документа установленного образца на специальных платорормах онлайн-обучения (например, Mirapolis или Moodle (Modular Object-Oriented Dynamic Learning Environment) _ модульная объектно-ориентированная Аинамическая среда)). Богатый фрункционал (наличие мичного кабинета, в котором размещены учебные материалы и инорормация о выполнения обучающимся образовательной программы, по которой он проходит обучение, возможности обучения в фрормате вилеоконференций, вебинаров, использование ресурса внутреннего чата, наличие системы увеАомлений и извещений, возможность организации общения одновременно С несколькими пользователями и Ар.) позволяют человеку самому управлять своим развитием, самостоятельно выстраивать образовательный маршрут, темп обучения.

Специфока использования цифровых образовательных ресурсов в системе повышения квалиффикации позволяет активно осуществлять Аиссеминацию пеАагогического опыта, ввиАу открытости системы получения инорормации, быстроты передачи инорормационно-меАийного контента, оперативности обмена знаниями и качественной профрессиональной рефлексией. Можно констатировать весомый потенциал применения Аистанционных фоорм при проведении научно-методических мероприятий, использования электронных средств обучения, организации Аистанционного образования и повышения квалификации педагога-музыканта в области 
Методики исполнительства, органологии, музыкальной пеАагогики. Время и происходящие социокультурные изменения в обществе, корректировка образовательной стратегии государства будут постоянно вносить новые вызовы А^я педагога, поэтому вкАючение его в систему постоянного повышения квалифоикации с применением Аистанционных цифрровых образовательных технологий является непременным условием его успешности в профессии и в жизни.

\section{LITERATURE ( $\triangle$ UTEPATYPA)}

Gurev, S., (2018), Sovremennoie distancionnoe obuchenie: monografia (in Russian), RUSAINS, Moscow, Russia, p. 118 / [Гурьев С.В. Современное Аистанционное обучение: монография / С.В. Гурьев. - Москва: РУСАЙНС, 2018. - 118 с].

Maistrenko, E., Maistenko V. (2019), Akmelogia profesionalnoi deiatelnosti (in Russian), Surgut State University, Russia, p. 110 / [Акмеология профрессиональной деятельности: учебно-методическое пособие/ Е. В. Майстренко, В. И. Майстренко; Сургутский гос. ун-т, Сургутский гос. пеА. ун-т. - 2-е изА., перераб. и лоп. - Казань: Бук, 2019. - 110 c].

Podlasai, І., (2010), Energoinformacionnaia pedagogika (in Russian), Data-Skver Moscow, Russia, p. 424 / [Пол^асый И.П. Энергоинформационная педагогика / М.П. Подласый. - Москва: Аата-Сквер, 2010. - 424 с.: и^].

Rytov, D., (2019), Cifrovae obrazovatelnae resursi v podgotovke myzikanta-izpolnitelia (in Russian), Journal of theoretical and applied research «Vestnik of SaintPetersburg State University of Culturen, volume 3(40), ISSN: 2819-0303, pp. 135-139 / [Рытов А.А. Цифрровые образовательные ресурсы в полготовке музыкантаисполнителя // Вестник Санкт-Петербургского государственного института культуры. - 2019. - № 3(40). - 192 с. С.135-139].

Uvarov, A., Gable, E., Dvoretskaia, I., Uvarova, A., Frumina, I., (2019), Trudnosti i perspektivi cifrovoi transformacii obrazovania (in Rusiian), HSE University, Russia. P. 343 / [Трудности и перспективы цифровой трансформации образования/ A. Ю. Уваров, Э. Гейбл, И. В. Аворецкая и др.; пол реА. А. Ю. Уварова, И. А. Фрумина ; Нац. исслеА. ун-т «Высшая школа экономики», Ин-т образования. Москва: ИзА. АОМ Высшей школы экономики, 2019. - 343, [1] с. (Российское образование: Аостижения, вызовы, перспективы / науч. рел. Я. И. Кузьминов, И. А. Фрумин)].

\section{DMITRY RYTOV}

Saint-Petersburg State University of Culture, Russia rytovda@mail.ru 

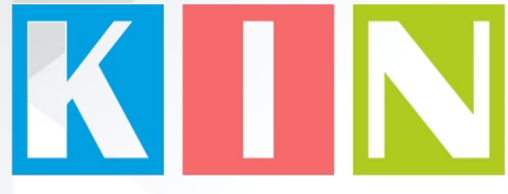

\section{ISSN: 2367-8038}

\section{Съставители \\ Петко Ст. Петков \\ Галина БогАанова}

Материалите в сборника са обект на авторско право. Разрешава се безвъзмезАното ползване на техни електронни/ хартиени копия само за мична употреба или обучение, при пьлно цитиране на текущата страница и слеА писмена Аек^арация от цитиращия за ^ипса на търговски намерения.

Научната поредица е регистрирана в НАЦИА С № 1209

() Авторски колектив, 2021

Техническо реАактори: Калина Сотирова-Вълкова Николай Ноев Паска^ Пиперков

\section{Editors}

Petko St. Petkov

Galina Bogdanova

This work is subject to copyright.

Open and free of charge use of digital/hard copies of publications is granted only for personal or educational use, with full citation of the current page, and after written declaration of the quoting side for notcommercial Intention.

Science series has been registered in NACID with No. 1209

() Authors` Group, 2021

Technical editors:

Kalina Sotirova-Valkova

Nikolay Noev

Paskal Piperkov

\section{ISSN: 2367-8038}

том 7, брой $1(10) / 2021$

vol. 7 , issue $1(10) / 2021$ 